DOI: 10.12731/2070-7568-2017-3-56-67

УДК 346.5

\title{
ПОЛИТИКА РОССИИ В АРКТИКЕ \\ В СФЕРЕ ПРОДОВОЛЬСТВЕННОЙ БЕЗОПАСНОСТИ
}

\author{
Трофимова С.А., Трофимова И.Б., \\ Трофимов Б.Н., Дмитриев М.Д.
}

В статье анализируются актуальные в современных условиях вопросы обеспечения продовольственной безопасности арктических регионов России, которые рассматривались на Международном Арктическом форуме 29-30 марта 2017 г. «АРКТИКА - территория диалога» и на Международной научно-практической конференции «Технологии развития сочииальных, экономических и логистических прочессов Арктической зонь России: история и современность» в Красноярске 30-31 марта 2017 года, проходившей в Красноярском государственном аграрном университете.

Особое внимание обращается на реальное обеспечение отдельных районов основными продуктами сельского хозяйства. Предлагаются меры по активному вовлечению населения арктических территорий и коренных малочисленных народов Крайнего Севера в самообеспечение продовольствием с использованием продукции традиционного природопользования коренных малочисленных народов.

Обосновывается комплексный подход к обеспечению населения северных территорий сибирской Арктики сбалансированным продовольствием в соответствии с направлениями продовольственной безопасности в мире, разработанными ООН в Декларации Тысячелетия.

Ключевые слова: продовольственная безопасность; Арктические территории; рациональные нормы потребления; продовольственная корзины; коренные малочисленные народы. 


\title{
RUSSIA'S FOOD SECURITY POLICY IN THE ARCTIC
}

\author{
Trofimova S.A., Trofimova I.B., \\ Trofimov B.N., Dmitriev M.D.
}

The article analyzes current food security issues across the Russian Arctic, which were considered at the International Arctic Forum "ARCTIC: Territory of Dialogue» on March 29-30, 2017 and at the International Scientific and Practical Conference "Technologies of Social, Economic and Logistic Processes of the Arctic zone of Russia: History and Modernity» held at the Krasnoyarsk State Agrarian University on March 30-31, 2017.

Particular attention is drawn to the practical provision of certain areas with basic agricultural products. Measures are proposed for the active involvement of the population of Arctic territories and indigenous peoples of the Far North in self-sufficiency of food with the use of products of traditional nature management of indigenous peoples. The complex approach to supplying the population of the northern territories of the Siberian Arctic with balanced food in accordance with the directions of food security in the world elaborated by the UN in the Millennium Declaration is substantiated.

Keywords: food security; Arctic territories; rational consumption norms; food baskets; indigenous peoples.

Правовая политика в отношении Арктических территорий формируется с учетом их значимости для безопасности Российской Федерации в целом на основе актов Президента РФ, Совета безопасности РФ и Правительства РФ.

При подготовке статьи были изучены документы стратегического планирования России, акты министерств и ведомств, публикации российских и иностранных авторов.

Наш взгляд на проблему продовольственной безопасности в Арктике [1] и важность оленеводства для коренных народов [2] подтвердили исследования канадских ученых. Данные Росстата по Красноярскому краю [3] позволили сделать некоторые выводы о потребностях населения Арктических территорий в продовольствии 
с учетом норм рационального потребления пищевых продуктов [4] и потребительской корзины Российской Федерации [5].

В исследованиях иностранных авторов: G.M. Butrico [6]; K.M. Lowitt [7]; Eriksen P. [8]; Nelson и др. [9] говорится о необходимости вовлекать местное население в обеспечение продовольственной безопасности. Российские специалисты Сибирского Федерального округа в сфере продовольственной безопасности населения северных территорий Т.В. Ахмадулина [10], Н. Копцева [11], А.А. Кондрашев и др. [12] разделяют этот подход.

Целью нашего исследования является изучение вопроса о возможности населения и коренных народов Севера участвовать в решении вопросов арктической продовольственной безопасности.

В Основах государственной политики России в Арктике на период до 2020 года и дальнейшую перспективу [13] и в Стратегии развития Арктической зоны Российской Федерации и обеспечения национальной безопасности на период до 2020 года (2013 г.) [14] к одному из приоритетных направлений относится комплексное социально-экономическое развитие Арктической зоны Российской Федерации, которое невозможно без решения проблемы продовольственной безопасности.

Не способствуют ее решению некоторые акты, такие как Приказ Министерства сельского хозяйства России и изменения к ним, периодически запрещающие вылов рыбы определенными орудиями лова. Например, изменения от 2016 года к Приказу от 21 октября 2013 года N 385 «Об утверждении правил рыболовства для Дальневосточного рыбохозяйственного бассейна» [15]. Весной 2016 года такие изменения привели к срыву заготовки рыбы коренными народами на Дальнем Востоке. Пока приказ отменили, рыба ушла. Коренное население осталось без важной составляющей своего рациона питания.

Отсутствие изучения и систематизации традиционных знаний коренных малочисленных народов Крайнего Севера и Арктики может привести к подрыву продовольственной безопасности в регионе, примером чего является вспышка сибирской язвы на Ямале летом прошлого года. В соответствии с Указом Президента «Об утверждении Доктрины продовольственной безопасности Российской Федерации» последствия природных и техногенных чрезвычайных ситуаций являются агроэкологическим риском обеспечения продо- 
вольственной безопасности [16]. Во избежание таких рисков необходимо накапливать информацию о потенциально опасных местностях на основе традиционных знаний коренных народов, что позволит понизить риски и повысить уровень продовольственной безопасности.

Решать вопросы продовольственной безопасности необходимо с учетом возможностей населения Северных территорий в производстве основных сельскохозяйственных продуктов.

Для установления потребности населения Северных и Арктических районов в продовольствии мы проанализировали данные об основных видах продуктов питания: картофеле, овощах, мясе, молоке, яйцах, которые были произведены в этих районах (Туруханском, Эвенкийском, Таймырском Долгано-Ненецком) в 2015 году.

В рамках исследования мы изучили соотношение фактически произведенного продовольствия к рациональным нормам потребления [4] и нормам потребления продовольствия в потребительской корзине [5]. Это дало возможность установить объемы продовольствия необходимые к ввозу из других территорий.

Анализ возможностей самообеспеченности основными сельскохозяйственными продуктами питания населения Арктических территорий и районов Крайнего Севера Красноярского края в сравнении с рациональными нормами потребления пищевых продуктов и нормами потребительской корзины РФ свидетельствует, что население двух районов, Туруханского и Эвенкийского, самостоятельно удовлетворяет потребность в картофеле. По данным Росстата [3] его производится даже на 25-30\% больше, чем требуется по нормативам. За счет картофеля компенсируется недостаток в овощах, которых выращивается только на 18-25\% от нормативных потребностей. В Туруханском районе производится молока $40 \%$ от потребности. В Таймырском районе (наиболее удаленном и с самыми неблагоприятными условиями) самообеспеченность в молоке и яйцах составляет менее $1 \%$ от потребности.

Для удовлетворения потребности Таймырского Долгано-Ненецкого муниципального района в продовольствии требуется ввозить все виды сельскохозяйственной продукции. Многие из них можно ввозить из других районов Красноярского края. К обеспечению некоторыми видами продовольствия (растительное масло, сахар, чай, 
специи) необходимо привлекать другие регионы Российской Федерации или страны партнеры.

Остается не использованным потенциал коренных малочисленных народов в решении вопросов продовольственной безопасности арктических территорий в части обеспечения мясом (оленина, лосятина), рыбой из рек и озер, ягодой, орехом и другими дикоросами.

Население Северных территорий и коренные народы необходимо шире привлекать к обеспечению продовольственной безопасности через формирование муниципального и государственного заказа на поставку природного продовольствия. Об этом говорят многие зарубежные исследователи, в частности, Gina Marie Butrico, подчеркивают необходимость вовлекать население арктических территорий и местные ресурсы в обеспечение продовольственной безопасности [6].

Специалист по продовольственной безопасности Канады и Ньюфаундленда Kristen N. Lowitt [7], ссылается на исследования Eriksen P. [8], Nelson C. и др. [9] и также подчеркивает необходимость учитывать вклад местных промыслов в обеспечение продовольственной безопасности общин коренного населения.

Важным аспектом продовольственной безопасности является также элементный состав продуктов питания. В Красноярском крае, по данным Центра биотической медицины, главные дефицитные элементы - кобальт, магний, медь, йод. О способах восполнения их дефицита авторы указывали в более ранних публикациях [17].

Исследования Н. Доршаковой, профессора Петрозаводского госуниверситета подтверждают аналогичный элементный дефицит в Карелии. Кроме того энергетические затраты на Севере «в энергии на 10-15\% выше, чем у жителей других климатических зон» [18], что требует больших объемов питания для их восполнения. Руководитель Роспотребнадзора Анна Попова выступая на Международном арктическом форуме «Арктика - территория диалога» 2017 г., отметила необходимость обновления рациона питания для детей Северных и Арктических территорий [19].

Обеспечение арктической продовольственной безопасности предъявляет широкий спектр требований от соблюдения «Пяти важнейших принципов безопасного питания», разработанных Всемирной Организацией Здравоохранения [20] до учета возможно- 
стей самообеспечения населения и вовлечения в процесс коренных народов, их традиционных форм жизнедеятельности: охоты, рыболовства, оленеводства и др. [21].

В стратегиях и программах продовольственной безопасности и развития Арктики необходимо учитывать интересы коренных малочисленных народов в социальной и экономической сферах, которые исследуются в статьях сибирских авторов: Копцевой Н. [11], Кондрашева А. и др. [12].

Необходимо развивать правовую политику Российской Федерации в направлении обновления нормативных актов, оставшихся со времен СССР и разработки новых, отражающих политику Российской Федерации в Арктике. Жизнь требует принятие Федеральных Законов, регулирующих различные аспекты деятельности субъектов, осваивающих Арктические территории с учетом интересов населения и коренных малочисленных народов.

Публикация подготовлена в рамках выполнения программы исследований при финансовой поддержке Краевого государственного автономного учреждения «Красноярский краевой фонд поддержки научной и научно-технической деятельности».

\section{Список литературы}

1. Food Security across the Arctic / Background paper of the Steering Committee of the Circumpolar Inuit Health Strategy Inuit Circumpolar Council -Canada, 2012, P.3 http://www.inuitcircumpolar.com/ uploads/3/0/5/4/30542564/icc_food_security_across_the_arctic_ may_2012.pdf (дата доступа 28.07.2017).

2. Food Insecurity: Arctic Heat Is Threatening Indigenous Life. http:// e360.yale.edu/feature/arctic_heat_threatens_indigenous_life_climate_ change/2974/ (дата доступа 28.07.2017).

3. Росстат // Официальный сайт URL: http://www.gks.ru/ (дата доступа 28.07.2017).

4. Приказ Министерства здравоохранения и социального развития РФ от 2 августа 2010 г. № 593н «Об утверждении рекомендаций по рациональным нормам потребления пищевых продуктов, отвечающим современным требованиям здорового питания» // СПС 
«Консультант плюс». http://www.consultant.ru/document/cons_doc_ LAW_105725/ (по состоянию на 28.07.2017).

5. Федеральный закон от 03.12.2012 № 227-Ф3 «О потребительской корзине в целом по Российской Федерации» // СПС «Консультант плюс». http://www.consultant.ru/document/cons_doc_LAW_138547/ (по состоянию на 28.07.2017).

6. Gina Marie Butrico Food Security and Identity: Iceland A thesis submitted to Kent State University in partial fulfillment of the requirements for the degree of Master of Arts https://etd.ohiolink.edu/pg_10?0::NO:10:P10_ ACCESSION_NUM:kent1374943947 (дата доступа 28.07.2017).

7. Kristen N. Lowitt A Coastal Foodscape: Examining the Relationship Between Changing Fisheries and Community Food Security on the West Coast of Newfoundland. http://dlc.dlib.indiana.edu/dlc/handle/10535/9673 (дата доступа 28.07.2017).

8. Ericksen P.J. 2008. What is the vulnerability of a food system to global environmental change? Ecology and Society 13(2): 14. [online]. http://www. ecologyandsociety.org/vol13/iss2/art14/ (дата доступа 28.07.2017).

9. Nelson C.H., Lowitt K., Nagy M., \& Bavington D. (2013). Future research approaches to encourage small-scale fisheries in the local food movement. Journal of Agriculture, Food Systems, and Community Development, 3(4), 177-181. DOI: http://dx.doi.org/10.5304/ jafscd.2013.034.020 (дата доступа 28.07.2017).

10. Ахмадулина Т.В. Анализ самообеспеченности Сибирского Федерального округа основными видами продовольствия // Молодой ученый. 2012. №11. С. 143-147. http://moluch.ru/archive/46/5574/ (дата доступа 28.07.2017).

11. Koptseva N. The current economic situation in Taymyr (the Siberian Arctic) and the prospects of indigenous peoples' traditional economy // Economic Annals-XXI. 2015. No. 9-10, 95-97.

12. Kondrashev A.A., Nikitenko M.E., Trofimova I.B., Trofimova S.A., \& Gotsko L.G. (2016) Food Security of Arctic Territories Legal Regulation // Journal of Siberian Federal University. Humanities \& Social Sciences,9(9), 2184-2193.

13. Основы государственной политики Российской Федерации в Арктике на период до 2020 года и дальнейшую перспективу (утв. Президентом РФ 18.09.2008 № Пр-1969) // СПС «Консультант плюс». 
http://www.consultant.ru/document/cons_doc_LAW_119442/ (по состоянию на 28.07.2017).

14. Стратегия развития Арктической зоны Российской Федерации и обеспечения национальной безопасности на период до 2020 года (утв. Президентом РФ) // СПС «Консультант плюс». http://www.consultant. ru/document/cons_doc_LAW_142561/ (по состоянию на 28.07.2017).

15. Приказ Минсельхоза России от 21.10.2013 № 385 (ред. от 19.04.2016) «Об утверждении правил рыболовства для Дальневосточного рыбохозяйственного бассейна» // СПС «Консультант плюс». http:// www.consultant.ru/document/cons_doc_LAW_158838/(по состоянию на 28.07.2017).

16. Указ Президента РФ от 30.01.2010 № 120 «Об утверждении Доктрины продовольственной безопасности Российской Федерации» // СПС «Консультант плюс». http://www.consultant.ru/document/ cons_doc_LAW_96953/ (по состоянию на 28.07.2017).

17. Kondrashev A., Trofimova S., Trofimova I., Nikitenko M., Gotsko L. The Arctic States' Strategies and the Northern Regions' Food Security // Economic Annals-XXI: Volume 162, Issue 11-12, Pages: 32-37, February 28, 2017 DOI: https://doi.org/10.21003/ea.V162-07.

18. Власти улучшат питание детей на Крайнем Севере местными продуктами и овощами // TACC. http://tass.ru/obschestvo/4170217 (дата доступа 28.07.2017).

19. Глава Роспотребнадзора: необходимо пересмотреть рацион питания детей, живущих в Арктике // TACC. http://tass.ru/v-strane/4139385 (дата доступа 28.07.2017).

20. World Health Organization 2007 WHO Library Cataloguing-inPublication Data Five keys to safer food. World Health Organization. ISBN 9244594633 (NLM classification: WA 695).

21.Никитенко М.Е., Трофимова С.А., Трофимова И.Б. Отдельные вопросы законодательной регламентации традиционной хозяйственной деятельности коренных малочисленных народов Севера // Правовая политика и правовая жизнь. 2016. №4. С. 64-69.

\section{References}

1. Food Security across the Arctic / Background paper of the Steering Committee of the Circumpolar Inuit Health Strategy Inuit Circum- 
polar Council -Canada, 2012, P.3 http:/www.inuitcircumpolar.com/ uploads/3/0/5/4/30542564/icc_food_security_across_the_arctic may_2012.pdf (accessed 28.07.2017).

2. Food Insecurity: Arctic Heat Is Threatening Indigenous Life. http:// e360.yale.edu/feature/arctic_heat_threatens_indigenous_life_climate_ change/2974/ (accessed 28.07.2017).

3. Rosstat. http://www.gks.ru/ (accessed 28.07.2017).

4. Prikaz Ministerstva zdravoohranenija i social'nogo razvitija RF ot 2 avgusta 2010 g. № 593n «Ob utverzhdenii rekomendacij po racional'nym normam potreblenija pishhevyh produktov, otvechajushhim sovremennym trebovanijam zdorovogo pitanija» [Order of the Ministry of Health and Social Development of the Russian Federation of August 2, 2010 No. 593H «On approval of recommendations on rational norms for the consumption of food products that meet modern requirements for healthy nutrition»]. SPS «Konsul'tant pljus». http:// www.consultant.ru/document/cons_doc_LAW_105725/ (accessed 28.07.2017).

5. Federal'nyj zakon ot 03.12.2012 № 227-FZ «O potrebitel'skoj korzine v celom po Rossijskoj Federacii» [Federal Law of December 3, 2012 No. 227-FZ «On the consumer basket as a whole for the Russian Federation»]. SPS «Konsul'tant pljus». http://www.consultant.ru/document/ cons_doc_LAW_138547/(accessed 28.07.2017).

6. Gina Marie Butrico Food Security and Identity: Iceland A thesis submitted to Kent State University in partial fulfillment of the requirements for the degree of Master of Arts https:/etd.ohiolink.edu/pg_10?0::NO:10:P10_ ACCESSION_NUM:kent1374943947 (accessed 28.07.2017).

7. Kristen N. Lowitt A Coastal Foodscape: Examining the Relationship Between Changing Fisheries and Community Food Security on the West Coast of Newfoundland. http://dlc.dlib.indiana.edu/dlc/handle/10535/9673 (accessed 28.07.2017).

8. Ericksen P.J. 2008. What is the vulnerability of a food system to global environmental change? Ecology and Society 13(2): 14. http://www. ecologyandsociety.org/vol13/iss2/art14/ (accessed 28.07.2017).

9. Nelson C.H., Lowitt K., Nagy M., \& Bavington D. (2013). Future research approaches to encourage small-scale fisheries in the local 
food movement. Journal of Agriculture, Food Systems, and Community Development, 3(4), 177-181. DOI: http://dx.doi.org/10.5304/ jafscd.2013.034.020. http://dx.doi.org/10.5304/jafscd.2013.034.020 (accessed 28.07.2017).

10. Ahmadulina T.V. Molodoj uchenyj. 2012. №11, pp. 143-147. http://moluch.ru/archive/46/5574/ (accessed 28.07.2017).

11. Koptseva N. The current economic situation in Taymyr (the Siberian Arctic) and the prospects of indigenous peoples' traditional economy. Economic Annals-HHI. 2015. No. 9-10, 95-97.

12.Kondrashev A.A., Nikitenko M.E., Trofimova I.B., Trofimova S.A., \& Gotsko L.G. (2016) Food Security of Arctic Territories Legal Regulation. Journal of Siberian Federal University. Humanities \& Social Sciences, 9(9), 2184-2193.

13. Osnovy gosudarstvennoj politiki Rossijskoj Federacii v Arktike na period do 2020 goda i dal'nejshuju perspektivu (utv. Prezidentom RF 18.09.2008 № Pr-1969) [The fundamentals of the state policy of the Russian Federation in the Arctic for the period until 2020 and for the future (approved by the President of the Russian Federation on September 18, 2008 No. Pr-1969)]. SPS «Konsul'tant pljus». http:// www.consultant.ru/document/cons_doc_LAW_119442/(accessed 28.07.2017).

14. Strategija razvitija Arkticheskoj zony Rossijskoj Federacii i obespechenija nacional'noj bezopasnosti na period do 2020 goda (utv. Prezidentom RF) [Strategy for the development of the Arctic zone of the Russian Federation and ensuring national security for the period until 2020 (approved by the President of the Russian Federation)]. SPS «Konsul'tant pljus». http://www.consultant.ru/document/cons_doc_LAW_142561/ (accessed 28.07.2017).

15.Prikaz Minsel'hoza Rossii ot 21.10.2013 № 385 (red. ot 19.04.2016) «Ob utverzhdenii pravil rybolovstva dlja Dal'nevostochnogo rybohozjajstvennogo bassejna» [Order of the Ministry of Agriculture of Russia of 21.10.2013 No. 385 (Edited on 19.04.2016) «On the Approval of Fishing Rules for the Far Eastern Fisheries Basin»]. SPS «Konsul tant pljus». http://www.consultant.ru/document/cons_doc_LAW_158838/ (accessed 28.07.2017). 
16. Ukaz Prezidenta RF ot 30.01.2010 № 120 «Ob utverzhdenii Doktriny prodovol'stvennoj bezopasnosti Rossijskoj Federacii» [Decree of the President of the Russian Federation of 30.01.2010 No. 120 «On Approving the Doctrine of Food Security of the Russian Federation»]. SPS «Konsul'tant pljus». http://www.consultant.ru/document/cons_doc_ LAW_96953/(accessed 28.07.2017).

17. Kondrashev A., Trofimova S., Trofimova I., Nikitenko M., Gotsko L. The Arctic States' Strategies and the Northern Regions' Food Security. Economic Annals-HHI. Volume 162, Issue 11-12, Pages: 32-37, February 28, 2017 DOI: https://doi.org/10.21003/ea.V162-07.

18. Vlasti uluchshat pitanie detej na Krajnem Severe mestnymi produktami $i$ ovosh hami [Authorities will improve the nutrition of children in the Far North with local products and vegetables]. TASS. URL: http://tass. ru/obschestvo/4170217 (accessed 28.07.2017).

19. Glava Rospotrebnadzora: neobhodimo peresmotret' racion pitanija detej, zhivushhih v Arktike [Head of Rospotrebnadzor: it is necessary to revise the diet of children living in the Arctic]. TASS. http://tass.ru/ v-strane/4139385 (accessed 28.07.2017).

20. World Health Organization 2007 WHO Library Cataloguing-in-Publication Data Five keys to safer food. World Health Organization. ISBN 9244594633 (NLM classification: WA 695).

21. Nikitenko M.E., Trofimova S.A., Trofimova I.B. Pravovaja politika $i$ pravovaja zhizn’. 2016. №4, pp. 64-69.

\section{ДАННЫЕ ОБ АВТОРАХ}

Трофимова Светлана Алексеевна, кандидат философских наук

Красноярский государственный аграрный университет пр. Мира, 90, г. Красноярск, 660049, Российская Федераџия Iness.kastilia@mail.ru

Трофимова Инна Борисовна, старший преподаватель кафедры теории и истории государства и права Красноярский государственный аграрный университет nр. Мира, 90, г. Красноярск, 660049, Российская Федераџия Iness.kastilia@mail.ru 
Трофимов Борис Николаевич, доцент кафедры философии Сибирский государственный университет науки и технологий имени академика М.Ф. Решетнева просп. имени газеть Красноярский Рабочий, 31, г. Красноярск, 660037, Российская Федерачия

Дмитриев Максим Дмитриевич, магистрант кафедры теории и истории государства и права Красноярский государственный аграрный университет пр. Мира, 90, г. Красноярск, 660049, Российская Федерация Dmitriev.m.d@gmail.com

\section{DATA ABOUT THE AUTHORS}

\section{Trofimova Svetlana Alekseevna, $\mathrm{PhD}$}

Krasnoyarsk State Agrarian University

90, Mira Ave., Krasnoyarsk, 660049, Russian Federation Iness.kastilia@mail.ru

Trofimova Inna Borisovna, Senior Lecturer, Chair of Theory and History of State and Law Krasnoyarsk State Agrarian University 90, Mira Ave., Krasnoyarsk, 660049, Russian Federation Iness.kastilia@mail.ru

Trofimov Boris Nikolaevich, Associate Professor of the Department of Philosophy

Siberian State University of Science and Technology named after Academician M.F. Reshetnev

31, Krasnoyarsk Worker Ave., Krasnoyarsk, 660037, Russian Federation

Dmitriev Maksim Dmitrievich, Master of Science in the Department of Theory and History of State and Law Krasnoyarsk State Agrarian University 90, Mira Ave., Krasnoyarsk, 660049, Russian Federation Dmitriev.m.d@gmail.com 